\title{
Results of Treatment of Distal Radius Fracture in Geriatrics Patients Using Closed Reduction and Percutaneous K-Wires Fixation
}

\author{
Hesham Hamed Refai, Morsy Mohammed Basiony, Moataz Bellah Yousef Salh Ahmed* \\ Department of Orthopedic Surgery, Aswan University, Egypt \\ *Corresponding Author: Moataz Bellah Yousef Salh Ahmed, Phone: 01114423341, Email: motaz.yousef@gmail.com
}

\begin{abstract}
Background: distal radius fractures are a common fracture among geriatric population. Requiring comprehensive understanding of fracture anatomy and comprehensive selection of method of treatment.

Aim: aim of this study is to observe treatment of unstable distal radius fracture by closed reduction and percutaneous pinning among old age. Patients and Methods: prospective study for analysis of 30 patients above age of 50 suffering from distal radius fracture and managed by closed reduction and percutaneous pinning in Aswan university hospital. After acceptable reduction of the fracture was achieved, two or more percutaneous K-wires were inserted through the distal radius with the wrist in traction to maintain the reduction. All cases were assessed by Gartaland and Werely score and by radiological assessment. Patients were followed up for a period of about 6 months.

Results: the majority of cases were women (70\%). Majority of the patients (76.6\%) sustained the injury due to fall. The side of involvement was predominantly the right side (60\%). According to scoring system of cases; NO excellent results (36.7\%), scored Good (50\%), scored Fair (13.3\%), and scored Poor at the end of 6 months follow up.

Conclusion: closed reduction and percutaneous pinning of distal radius fracture can considered as a satisfactory treatment in old age group and doesn't give an excellent results after short period of follow up.

Keywords: Distal radius fracture, Closed reduction, Percutaneous Kirschner wire fixation, geriatrics.
\end{abstract}

\section{INTRODUCTION}

One of popular surgical options for unstable distal radius fractures is closed reduction and percutaneous k-wires with or without external fixation ${ }^{(\mathbf{1})}$. Also open reduction and internal fixation (ORIF) with dorsal, volar and fragment specific approaches ${ }^{(2)}$.

Comminuted fractures of the distal end of the radius are usually caused by high-energy trauma in young patients and by low-energy trauma in the elderly, and presents as shear and impacted fractures of the articular surface of the distal radius with displacement of the fragments ${ }^{(3)}$. An articular step of $>2 \mathrm{~mm}$ will result in painful radiocarpal arthrosis ${ }^{(4)}$. A persistent dorsal tilt results in incongruity in the distal radioulnar joint (DRUJ), and changes in the transfer of force with dorsal overload and secondary carpal bone disease ${ }^{(5)}$. Nonoperative treatment was producing too many unsatisfactory results, up to $30 \%$ in large surveys ${ }^{(6)}$. In elderly VLP, but not k-wires fixation, can maintain surgically corrected ulnar variance in distal radius fractures, independent of the degrees of initial ulnar variance. VLP enhances earlier recovery in range of motion and grip strength than k-wirs ${ }^{(7)}$. This technique minimize morbidity in the elderly population by successfully handling osteopenic bone, allowed early return to function, provided good final results, and was associated with a low complication rate ${ }^{(8)}$.

\section{PATIENTS AND METHODS}

This is a prospective study for thirty patients above age of fifty suffering from distal radius fracture.
All patients were treated by closed reduction and percutaneous pinning with k-wires in Aswan University hospital in the period between April 2017 and May 2018.

\section{Inclusion criteria}

Inclusion criteria were sustained a fracture of the distal radius (extra-articular and intra-articular), they were over the age of fifty years, the patients presented within 2 weeks of injury.

\section{Exclusion criteria}

Exclusion criteria were open fracture with a Gustillo-Anderson ${ }^{\left({ }^{9}\right)}$ grading greater than 1, fractures which require open reduction / ligamentotaxis (external fixator).

A. Preoperative:

1. History:

Personal history: Name, Age, Sex, Occupation, Dominant side.

Past history: Details of previous disease or injury to the affected wrist and history of present symptoms:

1. Complain: Pain, swelling, finger anesthesia Mechanism of injury:

1. Fall outstretched on hand, Road traffic accident, others.

\section{Clinical examination:}

Throughout examination of ipsilateral elbow and shoulder was done.

\section{Wrist examination:}

Neurological examination: median-ulnar nerves.

Vascular examination: capillary refill. 
Results of Treatment of Distal Radius Fracture...

\section{Investigations:}

Routine Laboratory tests e.g. CBC,Renal and liver functions. views.

Radiological evaluation: Plain X-rays; PA and Lateral

CT (if needed).

\section{First aid treatment:}

The fractured limb was splinted in a cockup splint.

- Analgesic and anti-edematous measures were given.

- Patients were put under observation in the hospital till time of surgery with controlling of any associated medical condition.

B. Operative:

Surgical procedure:

Surgery was done under general or brachial block anesthesia and received prophylactic antibiotics within one hour of surgery. The patient is positioned in a supine position on a standard operating table. The patient's hand, wrist and forearm are prepared and draped.

\section{Surgical technique:}

The patient was placed in the supine position. An accurate reduction of the fracture was the first step in the treatment plan. A neutral position of the wrist was desirable. With a dorsally displaced fracture, the reduction was performed by pushing the distal fragment distally and palmary while holding the proximal fragment with the fingers around the forearm.

Image intensification fluoroscopy was used to assist the reduction and to assess the accuracy of the reduction. After acceptable reduction of the fracture was achieved, two percutaneous $\mathrm{K}$-wires were inserted through the radial styloid in divergent manner with the wrist in traction to maintain the reduction.

Image intensification fluoroscopy was used to assist the insertion of the $\mathrm{K}$-wires throughout the entire procedure. The wires were drilled proximally through the radial styloid until they penetrated the intact cortex of the shaft. K-wires with a diameter of 1.5 to $2.0 \mathrm{~mm}$ were selected for use, with smaller wires for women and larger wires for men.

The wire insertion was performed with a power Kwire driver to allow the surgeon to hold part of the reduction with one hand during $\mathrm{K}$-wire insertion dressing was applied cotton padding then plaster.

\section{Postoperative protocol \& Follow up:}

Post-operative analgesia is given up. Patient was encouraged to begin active finger movements as soon as the effect of anesthesia wore out. The limb was kept strictly elevated for a period of 2 days, postoperative plain $\mathrm{x}$-ray: P-A and lateral view for radiographic evaluation.

\section{Radiographic assessment:}

* AP view \& Lateral view

The patient discharged at the day after surgery after given instructions and date of follow up.
Final assessment and Follow up:

- First visit was after 2 weeks to check reduction, cast loosening, pain degree.

- The second visit after 5 weeks for cast and wire removal check x-ray for reduction, handgrip, wrist, and finger exercise, and physiotherapy consultation.

- Third visit after 24 weeks for radiological assessment as mentioned before and for clinical assessment.

- Clinical assessment: All patients were assessed by Sarmiento et al. ${ }^{(10)}$ modification of demerit point system of Gartland and Werley ${ }^{(11)}$ table (1).

Table (1): Functional analysis Sarmiento et $\boldsymbol{a l} .{ }^{(10)}$ modification of demerit point system of Gartland and Werley $^{(11)}$ )

\begin{tabular}{|l|l|}
\hline Prominent ulnar styloid & 1 \\
\hline Residual dorsal tilt & 2 \\
\hline Radial deviation of hand & $2-3$ \\
\hline Point range & $0-3$ \\
\hline \multicolumn{2}{|c|}{ Subjective evaluation } \\
\hline $\begin{array}{l}\text { Excellent - No pain, disability or limitation } \\
\text { of movement }\end{array}$ & 0 \\
\hline $\begin{array}{l}\text { Good - Occasional pain, slight limitation of } \\
\text { motion, no disability }\end{array}$ & 2 \\
\hline $\begin{array}{l}\text { Fair - Occasional pain, some limitation of } \\
\text { motion, feeling of weakness in the wrist, no } \\
\text { particular disability if careful, activities } \\
\text { slightly restricted }\end{array}$ & 4 \\
\hline $\begin{array}{l}\text { Poor - Pain, limitation of motion, disability, } \\
\text { activities more or less markedly restricted }\end{array}$ & 6 \\
\hline \multicolumn{2}{|c|}{ End result point ranges } \\
\hline Loss of dorsiflexion & $0-2$ \\
\hline Loss of ulnar deviation & 3 \\
\hline Loss of supination & 3 \\
\hline Loss of palmar flexion & 2 \\
\hline Loss of radial deviation & 1 \\
\hline Loss of circumduction & 1 \\
\hline Loss of pronation & 1 \\
\hline Pain in DRUJ & 2 \\
\hline Grip strength - 60\% or less of opposite side & 1 \\
\hline Point range & $0-8$ \\
\hline \multicolumn{2}{|c|}{} \\
\hline Excellent & 21 \\
\hline Good and \\
\hline Fair above \\
\hline Poor & $0-2$ \\
\hline
\end{tabular}

D.

\section{E. Statistical analysis}

Statistical analysis was done using SPSS version 24.0 with statistical significance level of 5\% $(\mathrm{P}<$ _0.05) For statistical analysis of the collected data, descriptive statistical methods (mean, \pm standard deviation) and 
independent samples $\mathrm{T}$ test will be used for comparison of quantitative data. And Chi-square test will be used for comparisons of quantitative data.

F. Ethical and Approval statements:

The study has been approved by the Ethical Committee of Faculty of Medicine, Aswan University. Informed consent with risk explanation has been obtained from all participating patients. Patients were free to refuse participation in the study without affecting the service or the clinical management. They have been free to ask any question about the study. Privacy and confidentiality of all data were assured.

\section{RESULTS}

The majority of cases were women. (70\%) Majority of the patients (76.6\%) sustained the injury due to fall. The side of involvement that was predominant is the right side (60\%).table(2) According to scoring system cases NO excellent results (36.7\%) scored Good (50\%) scored Fair (13.3\%) scored Poor at the end of 6 months follow up (table 3).

Table (2): demographic data.

\begin{tabular}{|c|l|l|l|}
\cline { 3 - 4 } \multicolumn{2}{c|}{} & $\begin{array}{l}\text { Number } \\
\text { of cases }\end{array}$ & Percentage \\
\hline \multirow{2}{*}{$\begin{array}{c}\text { Sex } \\
\text { distribution }\end{array}$} & Male & 9 & $30 \%$ \\
\cline { 2 - 4 } & Female & 21 & $70 \%$ \\
\hline \multirow{2}{*}{$\begin{array}{c}\text { Mode of } \\
\text { Injury }\end{array}$} & Fall & 23 & $76.67 \%$ \\
\cline { 2 - 4 } & RTA & 5 & $16.70 \%$ \\
\cline { 2 - 4 } & Other & 2 & $6.70 \%$ \\
\hline $\begin{array}{c}\text { Side } \\
\text { Involved }\end{array}$ & Left & 12 & $40 \%$ \\
\cline { 2 - 4 } & Right & 18 & $60 \%$ \\
\hline $\begin{array}{c}\text { Associated } \\
\text { Injuries }\end{array}$ & No & 27 & $90 \%$ \\
\cline { 2 - 4 } & Yes & 3 & $10 \%$ \\
\hline \multirow{2}{*}{}
\end{tabular}

Table (3): subjective evaluation

\begin{tabular}{|c|c|c|}
\hline \multicolumn{2}{|c|}{ Subjective evaluation } & End result \\
\hline \multicolumn{2}{|c|}{ Number of cases } & Number of cases \\
\hline Excellent & $\mathbf{0}$ & \\
\hline Good & $\mathbf{1 6}(\mathbf{5 3 . 3 \%})$ & $\mathbf{1 1}(\mathbf{3 6 . 6 7 \%}$ \\
\hline Fair & $\mathbf{9 ( 3 0 . 0 \% )}$ & $\mathbf{1 5}(\mathbf{5 0 \%})$ \\
\hline Poor & $\mathbf{5 ( 1 6 . 7 \% )}$ & $\mathbf{4 ( 1 3 . 3 3 \% )}$ \\
\hline
\end{tabular}

\section{Postoperative data:}

\section{* Postoperative radiographic evaluation:}

a. Radial height:

The mean radial height post-operative wase 11 with $\mathrm{SD} \pm 1.2$.

\section{b. Radial inclination:}

The mean radial inclination post operatively was 18 with $\mathrm{SD} \pm 3.8$

\section{c. Palmar inclination:}

Postoperative mean palmar inclination was 11.3 with $\mathrm{SD} \pm 6.2$.

\section{d. Ulnar variance:}

Interpretation of 2 nd day post-operative x-rays reveal 18 cases with neutral ulnar variance and 12 cases with negative ulnar variance.

\section{Post-operative complication}

Post-operative complications were counted in six cases. Four cases had pin tract infection that eradicated with antibiotics in all cases through follow up. Two cases had loss of reduction and refused revision, two cases had carpal tunnel syndrome, and one had superficial radial nerve numbness (Table 4).

Table (4): Post-operative complication

\begin{tabular}{|l|c|l|c|}
\hline $\begin{array}{l}\text { Post-operative } \\
\text { complication }\end{array}$ & NO. & Management & Percentage \\
\hline $\begin{array}{l}\text { Pin tract } \\
\text { infection }\end{array}$ & 4 & antibiotics & $13 \%$ \\
\hline $\begin{array}{l}\text { loss of } \\
\text { reduction }\end{array}$ & 2 & refused revision & $6.60 \%$ \\
\hline Carpal tunnel & 2 & $\begin{array}{l}\text { corticosteroid } \\
\text { injection after } \\
\text { complete union }\end{array}$ & $6.60 \%$ \\
\hline $\begin{array}{l}\text { Superficial } \\
\text { radial nerve } \\
\text { numbness }\end{array}$ & 1 & nurotonics & $3.30 \%$ \\
\hline Total & 6 & ----------- & $20 \%$ \\
\hline
\end{tabular}

Difference between mean of radiological parameter post-operative and after 6 months follow up: table (5)

Table (5): mean radiological parameter post-operative and after 6 months follow up.

\begin{tabular}{|l|l|l|l|l|l|}
\hline $\begin{array}{l}\text { Mean radial } \\
\text { height }\end{array}$ & \multicolumn{2}{|l|}{$\begin{array}{l}\text { Mean radial } \\
\text { inclination }\end{array}$} & \multicolumn{2}{|l|}{$\begin{array}{l}\text { Mean palmar } \\
\text { inclination }\end{array}$} \\
\hline $\begin{array}{l}\text { post- } \\
\text { operative }\end{array}$ & $\begin{array}{l}\text { Follow } \\
\text { up }\end{array}$ & $\begin{array}{l}\text { post- } \\
\text { operative }\end{array}$ & $\begin{array}{l}\text { follow } \\
\text { up }\end{array}$ & $\begin{array}{l}\text { post- } \\
\text { operative }\end{array}$ & $\begin{array}{l}\text { follow } \\
\text { up }\end{array}$ \\
\hline 11 & 8.33 & 18 & 14.6 & 11.3 & 9.6 \\
\hline
\end{tabular}

\section{Radiological parameters after 6 months}

a. Radial inclination:

Mean $=14.6 \mathrm{SD} \pm 6.57$

According to $\mathrm{T}$ - test there is statistically significant relationship between radial height and functional score $r$ (28) $=.709, \mathrm{p}<0.001$.

\section{b. Ulnar variance:}

The sum of number and percentage of cases according to ulnar variance had been calculated as in illustrated in the following table (6):

Table (6): distribution according to ulnar variance.

\begin{tabular}{|l|l|l|l|}
\hline & Neutral & Negative & Positive \\
\hline Cases & $\mathbf{1 7}$ & $\mathbf{3}$ & $\mathbf{1 0}$ \\
\hline Percentage & $\mathbf{5 6 . 7 \%}$ & $\mathbf{1 0 . 0 \%}$ & $\mathbf{3 3 . 3 \%}$ \\
\hline
\end{tabular}




\section{c. Palmar inclination:}

The mean palmar inclination was $=9.6$ with $\mathrm{SD} \pm$ 7.5 and by T-test there is statistically significant relationship between palmar inclination and functional score $r(28)=.778, p<0.003$.

\section{d. Radial height:}

The mean radial height was 8.033 with $\mathrm{SD} \pm 3.46$ and according to T-test there is statistically significant relationship between palmar inclination and functional score $\mathrm{r}(28)=.661, \mathrm{p}<0.006$.

\section{Final score:}

The mean of the score for cases treated by K-wires and cast was 12.23 with $\mathrm{SD} \pm 6.354$ According to scoring system cases Good cases was $36.67 \%$, Fair cases was $50 \%$ and Poor cases was $13.3 \%$

\section{ILLUSTRATIVE CASE}

Female patient, 63 years old, housewife, FOSH, with type $\mathrm{C} 1$ fracture of $\mathrm{Rt}$ distal radius, managed by closed reduction under general anesthesia and percutaneous kwires, wires are removed after 1.5 month, patient scored good figure $(1,2,3)$.

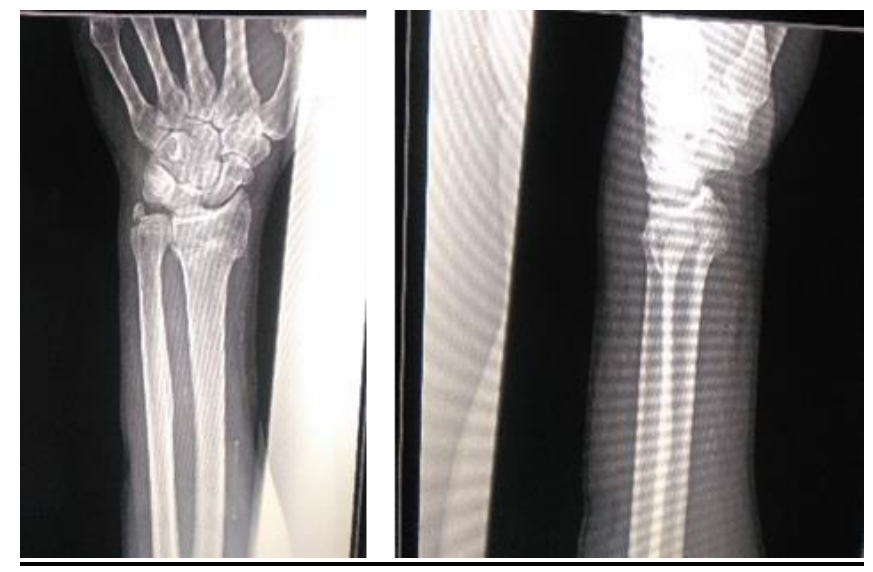

Figure (1): Pre-operative x-ray

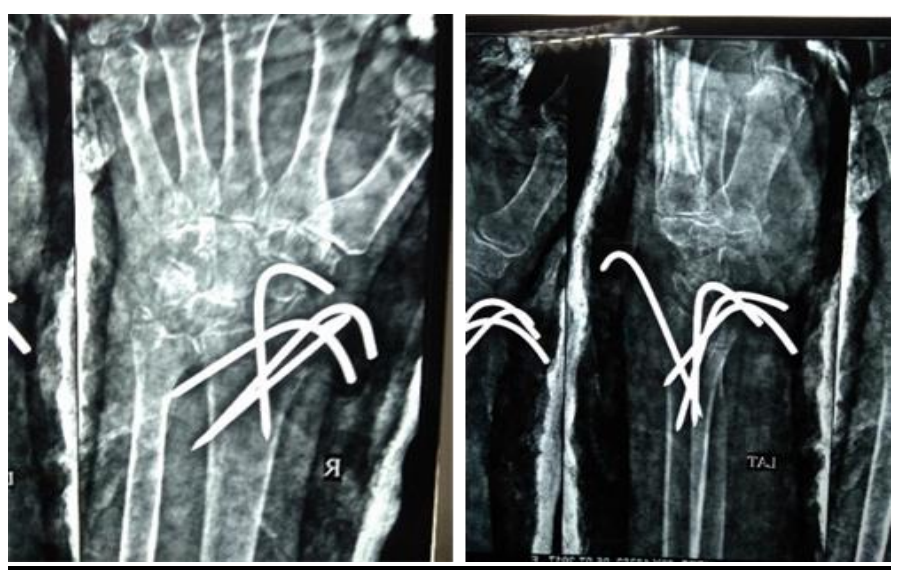

Figure (2): 3-week Post-operative $\mathrm{x}$ - ray

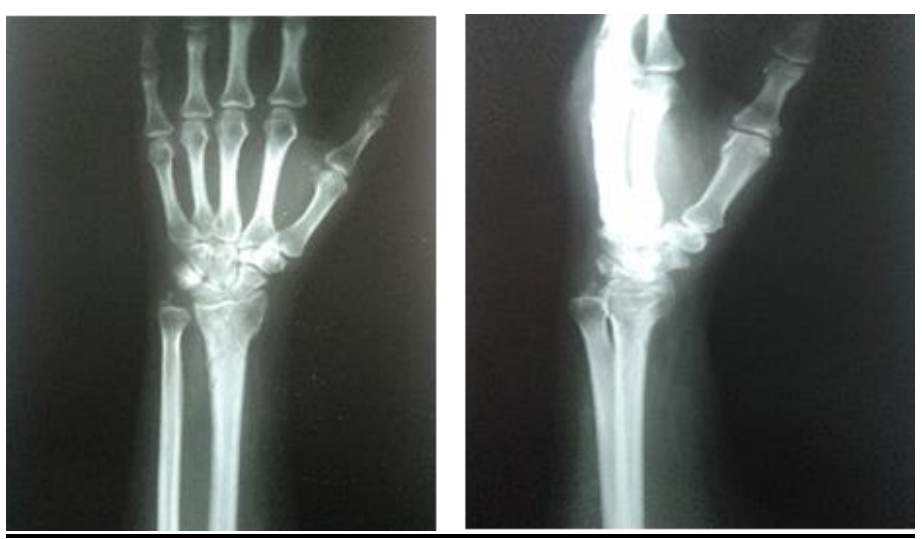

Figure (3): 4 months postoperative

Follow up complication:

Follow up complications were encounted in 5 cases mainly arthritis.

\section{DISCUSSION}

Distal radius fracture is common amonggeriatrics and old age people. usually comminuted distal radius fracture, particularly in the old osteoporotic patient, represent a difficult management problem without anobvious surgical answer. It is also representing onesixth of all fractures in the age group above $50^{(\mathbf{1 2})}$.

Dorsal comminution and significant displacement is considered as unstable fracture ${ }^{(\mathbf{1 3})}$.The traditional treatment of distal radius fractures in osteoporotic patients is closed reduction and immobilization in cast. this is method avoids surgery and relatedcomplications, but casts cannot maintain the lengthand rotation of the distal fragment particularly with comminution. ${ }^{(14)}$.Loss of reduction usually occurs after two weeks of initial closed reduction ${ }^{(15)}$.

usually $51.4 \%$ showing unsatisfactory result with closed reduction and cast in the treatment of comminuted interarticual fracture of distal radius ${ }^{(\mathbf{1 6})}$.

Other authors have suggested that the final functional outcome in old age patients with unstable DRFs has no direct relation to the radiographic outcome, and conservative methods had a satisfactory outcome ${ }^{(17)}$. non-operative management for fractures of the distal radius in low-demand patients older than 60 years, in study by Young and Rayanfound that no correlation between radiographic outcomes and functional outcomes.

Most of these included in that study were high-risk medically fragile patients with multiple comorbidities. Six of 10 were with intra-articular fractures developed progression of radiocarpal and distal radioulnar joint arthrosis. Only two with radiographic signs of arthrosis had an unsatisfactory clinical outcome. Persistent nerve symptoms were present in three of 25 patients (12\%). a clinical deformity (prominence of the ulnar head) was present in 14 of the 25 evaluated patients (56\%). None of the patients were dissatisfied with the appearance of the wrist. Gartland and Werley score revealed 22 patients (88\%) with excellent to good results and three patients 
(12\%) with fair or poor results. One patient developed a complex regional pain syndrome.

In other 14 studies (1306 patients) were in a review study, 10 of which were prospective. A percentage of $(50.5 \%)$ of patients underwent volar locking plating, while $(49.5 \%)$ were treated with k.wireNo differences were found regardingROM, grip strength, radiographic parametersand rate of complications. The conclusion was that no significant difference between ORIF over k-wires (18).

In other studies, 95 patientstreated by closed reduction and castwith mean age of69 years with comminuted distal radius fractures. two cases had apin-track infections and four caseshad a complex regional pain syndrome. $87 \%$ of patients had good or v. good Gartland scores, one poor result with persistent regional pain syndrome . three of them had suffered from impaired hand function. Eightyfive percent had less than $10^{\circ}$ dorsal tilt and less than 6 mm radial shortening after 28 months.

Ina prospective randomized study of 90 distal radius fractures patients with a mean age of 65 years. They hadnoticed no difference in satisfaction rate and functional outcome (Gartland score). External fixation maintained radial length better at 2 years with more rate of pin tract infection. The authors conclude that there was no final difference between these treatment methods. Both had a complication rate of $45 \%$.

In other study of 100 patients, the Kapandji Kwire method was compared with oblique radioulnar pinning with a mean age of 65 years. Results were found to be good to very good (using Martin score) for patient treated with the Kapandji K-wire method and satisfactory to good for patients treated with the oblique radioulnar Kwire method. Kapandji K-wires groups had better outcome after ten months follow-up. The complication rate was $30 \%$ in both methods .which mainly nerve irritation and wire migration. ${ }^{(19)}$.

In our study Evaluation of closed reduction and percutaneous pinning as a method of treatment of distal radius fracture in elderly patients:

We treated thirty patients with 63.7 years using this method. The mean of the score was 12.23 using Gartland \&werley score with SD \pm 6.354 According to scoring system. NO excellent result Good results was $36.3 \%$ Fair was $50 \%$ \&Poor was $13.3 \%$ evaluation of radiological parameters results significant correlation between palmar inclination radial height, radialinclination and the final functional score with $\mathrm{p}$ - value $\leq 0.05$.

There were decrease in different radiological parameters values at the end of follow up as compared to postoperative values, although it is still accepted. We recommend adding external fixator to highly comminuted fractures as previous studies show its superiority in preserving radial height values after two years.

Distal radius fracture in elderly usually came as isolated injury (90\%) this attributed to mechanism of trauma which usually falling on outstretched hands, which is low energy trauma $(76.76 \%)$. Most similar studies reveal better functional score than our study we can explain this by defect in compliance regarding physiotherapy by patients and short period of follow up (6 months).Actually, most patients continue to improve after 6 months and the patients will have better results after 2 years as noticed by other studies. We had a complication rate of $20 \%$, which is acceptable rate, and most complication can be treated easily. Most of our patients had been returned to their usual daily activity. Choosing method of fixation in distal radius fracture among elderly population requiring careful estimation of biological age of patient, his daily requirements and fracture pattern. The rate of recovery and limitations of daily living activities during treatment affect the quality of life for patients with distal radius fractures. In contrary with younger patients, the elderly experiences a delay of about 6 months in final functional outcome ${ }^{(20)}$.

\section{CONCLUSION}

Distal radius fracture is common fracture in elderly osteoporotic individual, usually low energy trauma. It's more common in females than males and can affect wrist and hand function tremendously. Closed reduction and percutaneous k-wire fixation is cheap and less invasive procedure that can give satisfactory results in elderly low demand population. Most complications are due to loss of normal parameters. Shortening of radius is more disabling than an angulatory deformity of the distal radius. Nonunion is extremely rare complication. There is no strong relationship between patient satisfaction and functional score or radiological parameters in this age group. ORIF may give early good result and return to activity but the results Semmes nearly similar after long follow up.

\section{REFERENCES}

1. Bajwa AS, Rammappa M, Lee L, Nanda R (2015): Treatment of unstable distal radius fractures: non-invasive dynamic external fixator versus volar locking platefunctional and radiological outcome in a prospective casecontrolled

series. https://www.ncbi.nlm.nih.gov/pmc/articles/PMC484 9219/

2. Ilyas AM (2011): Surgical approaches to the distal radius. Hand, 6(1): 8-17.

3. Rozental TD, Blazar PE (2006): Functional outcome and complications after volar plating for dorsally displaced, unstable fractures of the distal radius. The Journal of hand surgery, 31(3): 359-365.

4. Giwa L, Spacey K, Packer G (2015): Management of a complex, multioperated intra-articular distal radius fracture. Journal of wrist surgery, 4(03): 179-182.

5. Thomas BP, Sreekanth R (2012): Distal radioulnar joint injuries. Indian Journal of Orthopaedics. 46(5):493-504. 
6. Rikli DA, Businger A, Babst R (2005): Dorsal double-plate fixation of the distal radius. Operat Orthop Traumatol., 17:624-40.

7.McCamley CH, Peter T , Cheryl K, Steve Q, Amy W , Ruurd J (2016): Fractures of the Distal Radius: A Randomized Controlled Trial of 180 Patients Comparing Volar Locking Plates and Alternative Fixation Methods. Journal of Trauma \& Treatment, J Trauma Treat., 5:2

8.Kato $S$, Tatebe M, Yamamoto M, Iwatsuki K, Nishizuka T, Hirata $H$ (2014): The results of volar locking plate fixation for the fragility fracture population with distal radius fracture in Japanese women. Nagoya journal of medical science, 76(1-2):101.

9. Gustilo RB, Anderson JT (1976): Prevention of infection in the treatment of one thousand and twenty-five open fractures of long bones: retrospective and prospective analyses. J Bone Joint Surg Am.,58:453-458.

10.Sarmiento A, Pratt GW, Berry NC, Sinclair WF (1975): Colles' fractures. Functional bracing in supination. The Journal of bone and joint surgery. American volume, 57(3): 311-317.

11.Gartland JJ Jr, Werley CW (1951): Evaluation of healed colles fracture.J Bone Joint Surg Am., 33:895-907

12.Jupiter JB, Ring D, Weitzel PP (2002): Surgical treatment of redisplaced fractures of the distal radius in patients older than 60 years. The Journal of hand surgery, 27(4):714-723.

13.Walton NP, Brammar TJ, Hutchinson J, Raj D , Coleman NP (2001): Treatment of unstable distal radial fractures by intrafocal, intramedullary Kwires. Injury, 32(5): 383-389.
14. Weil WM, Trumble TE (2005): Treatment of distal radius fractures with intrafocal (Kapandji) pinning and supplemental skeletal stabilization. Hand clinics, 21(3): 317-328.

15.Fu YC, Chien SH, Huang PJ, Chen SK, Tien YC, Lin GT ,Wang GJ (2006): Use of an external fixation combined with the buttress-maintain pinning method in treating comminuted distal radius fractures in osteoporotic patients. Journal of Trauma and Acute Care Surgery, 60(2): 330-333.

16.Spira E, Weigl K (1968): The comminuted fracture of the distal end of the radius. Reconstr Surg Traumatol .,11:12838.

17.Young BT, Rayan G M (2000): Outcome following nonoperative treatment of displaced distal radius fractures in low-demand patients older than 60 years. The Journal of hand surgery, 25(1): 19-28.

18.Franceschi F, Franceschetti, E, Paciotti, M, Cancilleri, F, Maffulli, N, Denaro V(2015): Volar locking plates versus K-wire/pin fixation for the treatment of distal radial fractures: a systematic review and quantitative synthesis. British medical bulletin, 115(1): 91-110.

19.Gehrmann SV, Windolf J, Kaufmann RA (2008): Distal radius fracture management in elderly patients: a literature review. The Journal of hand surgery, 33(3): 421-429.

20.Handoll HH, Madhok R (2003): Conservative interventions for treating distal radial fractures in adults. https://www.ncbi.nlm.nih.gov/pubmed/12804395 